\title{
Understanding how pictures are seen is important for comparative visual cognition
}

\author{
Marcia L. Spetch \\ University of Alberta
}

Keywords: real world objects, pictures as surrogates, picture processing, birds, pigeons, artificial stimuli, visual cognition, comparative cognition

My motivation for co-authoring the target article (Weisman $\&$ Spetch, 2010) was two-fold. First, 1 hoped it would restimulate discussion and consideration of the questions, issues and limitations surrounding the use of pictures as surrogates for real world objects in comparative cognition research (Bovet \& Vauclair, 2000; Fagot, 2000). Second, I hoped it would encourage more research aimed at assessing the real world validity of findings from animal research using pictures. The commentaries on our target article reveal a spicy variety of reactions and opinions, which is encouraging for the first goal. The commentators made many excellent points, some which I agree with and some which I question. My coauthor, Ron Weisman has provided a detailed reply to many of the commentaries so I will limit my reply to a few selected points.

\section{Picture processing is not just perceptual}

The commentary by Fagot and Parron (2010) raises the excellent point that a failure to perceive correspondence between pictures and their referents can arise from more than just perceptual limitations. They convincingly argue, based on research with non-human primates, that presentation of stimuli that are perceptually appropriate to the species is Correspondence to Marcia Spetch, Department of Psychology, University of Alberta, Edmonton, Alberta, Canada. T6G 2E9. Email:mspetch@ualberta.ca not a sufficient condition for correspondence. I agree that even if careful attention is paid to making stimulus displays fully appropriate to the avian eye, birds may still fail to see correspondence due to conceptual limitations or insufficient experience.

Although we cannot assume that correspondence will be revealed by providing stimuli better suited to the avian eye, it is nevertheless the case that a stimulus display that is inappropriate for the species is unlikely to reveal abilities that may exist. In fact, studies with both children and brain damaged adults have shown that different abilities can be revealed with photorealistic pictures compared to degraded pictures or line drawings (e.g., Chainey \& Humphreys, 2001; Ganea, Bloom Pickard \& DeLoache, 2008). Therefore understanding the visual system of the species under investigation can help with finding the most appropriate stimuli to present, and the ones that are most likely to reveal abilities that do exist.

\section{Need for a picture processing framework}

Fagot and Parron (2010) also argue that the field is in need of a clear framework for describing differences in picture processing, and they suggest that the framework include a distinction between "independence", "confusion" and "equivalence" modes of processing pictures. I agree 
that a framework is needed and that these distinctions are important. I suggest that the framework be expanded to also include the distinction noted by Jitsumori (2010) between two dimensional (2D) and three dimensional (3D) processing of pictorial information. This distinction may be orthogonal to the picture processing modes proposed by Fagot and Parron and it might be particularly important when viewing pictures of unfamiliar objects. Consider an unfamiliar artificially created object such as the one shown in Figure 1. Most of you viewing this image would likely describe it as a cylindrical object with three attached parts. But what if you did not see the image as containing a 3D object?

Jitsumori (2010) discusses an example of a patient with

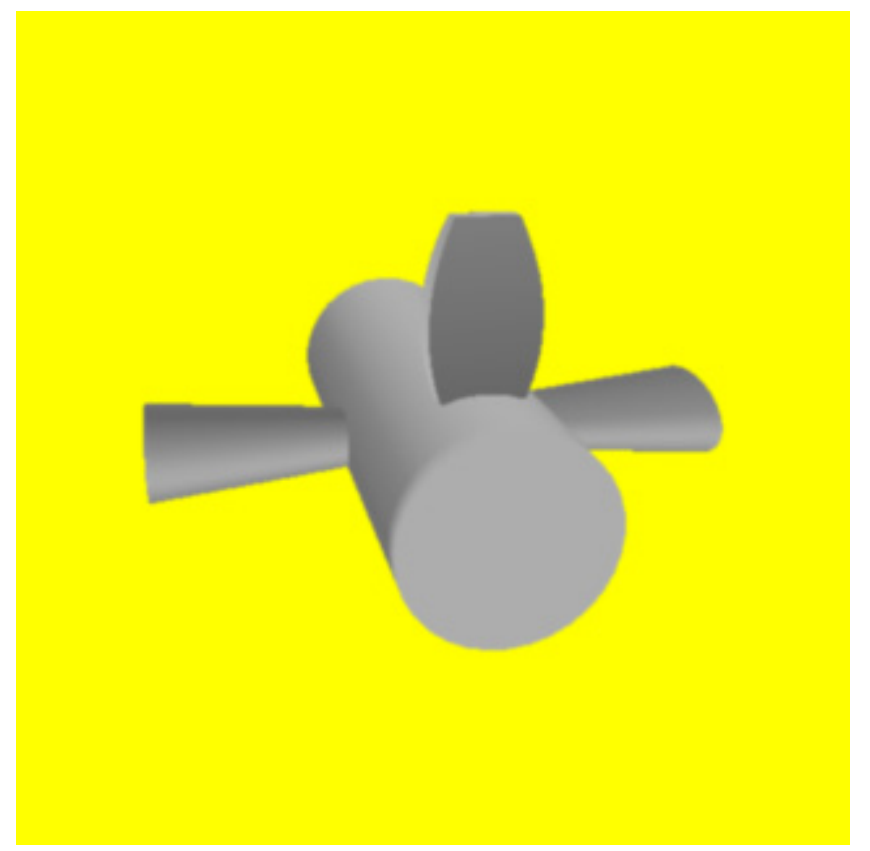

Figure 1. Example of an image of an unfamiliar 3D object. From: Spetch, Friedman \& Vuong, 2006. Dynamic Object Recognition in pigeons and humans. Learning \& Behavior, 34, 215-228.

visual agnosia who displayed a failure to derive 3D structure from pictorial depth cues in a 2D image. Another interesting example of a failure to process the 3D nature of objects in pictures is provided by a recent paper on recovery from blindness in humans (Ostrovsky, Meyers, Ganesh, Mathur \& Sinhain, 2009). In this study, an adult and two children were tested for their perception and parsing of objects shown in pictures following treatment for blindness that had occurred early in their life. These individuals showed perfect performance in parsing and reporting the number of objects in pictures of simple $2 \mathrm{~d}$ shapes as long as the objects did not overlap. However, they were not able to accurately report the number of objects when shown 3D shapes. For example, when shown a picture of a single cube with three surfaces indicated by lighting and shadows, they would report perceiving three objects, indicating that they did not integrate the surfaces into the perception of a single 3D object. Moreover, when tested for object recognition and parsing of scenes in colored photographs, they overfragmented the pictures into meaningless parts, apparently on the basis of luminance or hue. Thus, instead of seeing the object shown in Figure 1 as a cylinder with three attached parts, such individuals would likely report seeing a set of objects based on the various $2-\mathrm{d}$ shapes formed by luminance changes. Interestingly, Ostrovsky et al. (2009) found that motion greatly facilitated object recognition as well as the parsing and integration of objects. Parsing and recognition of static pictures also improved considerably for two of the individuals over a period of several months after regaining sight.

Of course, the individuals in Ostrovsky et al. (2009) had been deprived of all visual experience for much of their lives and so we cannot assume that animals, who have extensive experience with real world vision, would similarly fail to detect the $3 \mathrm{D}$ information in the image. But clearly, the informational content of a picture is influenced by whether or not the $3 \mathrm{D}$ information is processed. Although it may be safe to assume that the typical adult human perceives the 3D information in pictures, we need evidence to make this assumption in comparative cognition research. Therefore, studies of depth perception and object parsing in pictures (e.g., Cavoto \& Cook 2006; Lazareva \& Wasserman, 2007; Nagasaka \& Wasserman, 2008), similarity of results between real and pictures objects (Friedman, Spetch \& Ferrey, 2005), and correspondence between pictures and real objects (Spetch \& Friedman, 2006) are important for helping to determine whether or when birds perceive 3D information in pictures.

\section{Are questions about picture perception peripheral to the study of object recognition or categorization?}

Soto and Wasserman (2010) argue that the question of whether pigeons see correspondence between objects and their pictures "is of little broad relevance to research in object recognition and categorization" (pg. 13). I disagree and argue that the question should be central to this research. Consider a study that presents pigeons with pictures of people or birds for categorization. If pigeons respond to the pictures in either a confusion mode or an equivalence mode, then the way they categorize these stimuli tells us something about the processes by which they categorize people and birds. If they respond in the independence mode, but perceive them as novel 3D objects, then it tells us about how they 
categorize artificial unfamiliar objects that have particular structures, contours and colors. If they perceive them in the independence mode and do not perceive them as $3 \mathrm{D}$ objects, then it tells us about how they categorize pictures on the basis of $2 \mathrm{D}$ information. The processes under investigation, and the brain regions underlying these processes may be different in each of these cases as nicely illustrated by the research discussed by Jitsumori (2010; for additional examples, see Behrmann \& Kimchi, 2003; Gerlach, 2009; Vuilleumier, Henson, Driver, \& Dolan, 2002). Knowing whether animals see the 3D nature of objects in pictures, and whether they see correspondence between the information presented in pictures and information seen in the real world is important for knowing what recognition and categorization processes are being investigated.

I agree with Lazareva (2010) and with Soto and Wasserman (2010) that there are many good reasons for using controlled artificial stimuli in studies of animal learning and cognition. Use of such stimuli allows us to study basic processes and identify fundamental principles, which is clearly one of the goals of science. I also agree that scientific advances can and are being made in the field of comparative cognition with the use of artificial stimuli. Nevertheless, cognitive processes evolved to deal with problems in the real world. As revealed by the constraints on learning literature back in the 1960's, a full understanding of learning and cognitive processes is unlikely to be achieved without attention to the natural world in which these processes evolved. Determining the extent to which the pictures used in animal cognition research are seen as corresponding to the real world is important for making this contact.

The study of cognition can be approached from many different perspectives, with many different methods, and with many different goals. This is the spice of science, and I do not wish to argue that comparative cognition research using pictures or other artificial stimuli is not valuable. My own research program extensively uses such stimuli. However, we should not lose sight of the fact that pictures are not natural stimuli or of the need to test the external validity of findings. I hope that our target article will encourage more explicit acknowledgement that pictorial stimuli are artificial, and more research to determine whether or under what circumstances pigeons see pictures as images of $3 \mathrm{D}$ objects or examples of real-world categories.

\section{References}

Behrmann, M. \& Kimchi, R. (2003). What does visual agnosia tell us about perceptual organization and its relationship to object perception? Journal of Experimental Psychology: Human Perception and Performance, 29, 19-42. doi:10.1037/0096-1523.29.1.19
Bovet, D., \& Vauclair, J. (2000). Picture recognition in animals and humans. Behavioural Brain Research, 109, 143-165. doi:10.1016/S0166-4328(00)00146-7

Cavoto, B.R. \& Cook, R.G. (2006). The contribution of monocular depth cues to scene perception by pigeons. Psychological Science, 17, 628-634. doi:10.1111/j.14679280.2006.01755.x

Chainay, H. \& Humphreys, G.W. (2001) The realobject advantage in agnosia: Evidence for a role of surface and depth information in object recognition, Cognitive Neuropsychology, 18, 175-191. doi:10.1080/02643290042000062

Fagot, J. (2000). Picture perception in animals. London, Psychology Press.

Fagot, J., Parron, C. (2010). Picture perception in birds: Perspective from primatologists. Comparative Cognition \& Behavior Reviews, 5, 132-135. Retrieved from http://psyc.queensu.ca/ccbr/index.html doi:10.3819/ ccbr.2010.50007

Friedman, A., Spetch, M.L., \& Ferrey, A. (2005). Recognition by humans and pigeons of novel views of 3-D objects and their photographs. Journal of Experimental Psychology: General. 134, 149-162. doi:10.1037/0096-3445.134.2.149

Ganea, P.A., Pickard, M.B. \& DeLoache, J.S. (2008) Transfer between picture books and the real world by very young children. Journal of Cognition and Development, 9, 4666. doi:10.1080/15248370701836592

Gerlach, C. (2009). Category-specificity in visual object recognition. Cognition, 111, 281-301. doi:10.1016/j. cognition.2009.02.005

Jitsumori, M. (2010). Do animals recognize pictures as representations of 3D objects? Comparative Cognition \& Behavior Reviews, 5, 136-138. Retrieved from http://psyc. queensu.ca/ccbr/index.html doi:10.3819/ccbr.2010.50008

Lazareva, O. F. (2010). On categories, pictures, and the goals of comparative psychology. Comparative Cognition \& Behavior Reviews, 5, 139-142. Retrieved from http://psyc. queensu.ca/ccbr/index.html doi:10.3819/ccbr.2010.50009

Lazareva, O.F., Wasserman E.A. \& Biederman I. (2007) Pigeons' recognition of partially occluded objects depends on specific training experience. Perception 36, 33-48. doi:10.1068/p5583

Ostrovsky, Y., Meyers, E., Ganesh, S. Mathur, U \& Sinha, P. (2009). Visual parsing after recovery from blindness. Psychological Science, 20, 1484-1491. doi:10.1111/ j.1467-9280.2009.02471.x

Soto, F. A., \& Wasserman, E. A. (2010). Comparative Vision Science: Seeing Eye to Eye? Comparative Cognition \& Behavior Reviews, 5, 148-154. Retrieved from http://psyc. queensu.ca/ccbr/index.html doi:10.3819/ccbr.2010.50011

Spetch, M. L., and Friedman, A. (2006). Pigeons see correspondence between objects and pictures. Psychological Science, 17, 966-972. doi:10.1111/j.1467- 
9280.2006.01814.X

Vuilleumier,P., Henson, R.N., Driver, J. \& Dolan, R.J. (2002). Multiple levels of visual object constancy revealed by event-related fMRI of repetition priming. Nature Neuroscience, 5(5), 491-499. doi:10.1038/nn839

Weisman, R. G. (2010). The commentaries: Some are visual illusions. Comparative, Cognition and Behavior Reviews, 5, 155-162. Retrieved from http://psyc.queensu.ca/ccbr/ index.html doi: $10.3819 /$ ccbr.2010.50012

Weisman, R., Spetch, M. (2010) Determining when birds perceive correspondence between pictures and objects: a critique. Comparative, Cognition and Behavior Reviews, 5, 117-131. Retrieved from http://psyc.queensu.ca/ccbr/ index.html doi: $\underline{10.3819 / \mathrm{ccbr} .2010 .50006}$ 